
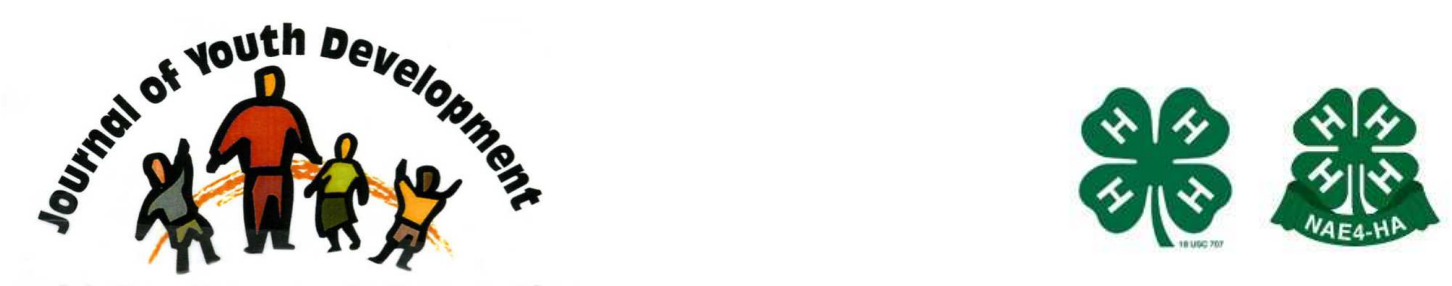

Bridging Research \& Practice

\title{
Reflections on a Century of Youth Development Research and Practice
}

\author{
Joyce A. Walker \\ University of Minnesota \\ walke007@umn.edu
}

Michelle Alberti Gambone

Youth Development Strategies, Inc.

Kathrin C. Walker

University of Minnesota 


\title{
JOURNAL OF YOUTH DEVELOPMENT \\ bridging research and practice

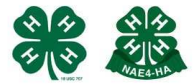

Volume 6, Number 3, Fall 2011

Article 110603FA001

\section{Reflections on a Century of Youth Development Research and Practice}

\author{
Joyce A. Walker and Kathrin C. Walker \\ University of Minnesota \\ Michelle Alberti Gambone \\ Youth Development Strategies, Inc.
}

\begin{abstract}
This introduction to the special issue highlights the youth development research and practice base that influenced the field in the $20^{\text {th }}$ century and presents some historical context for the practice and study of youth work. Next, it provides an overview of the articles which offer a retrospective account of youth development from how youth development has been studied, understood and measured to how youth development practice has evolved to support, engage and address the needs of young people. The introduction concludes with reflections stimulated by the process of reviewing the manuscripts and working with the authors on their contributions. Three themes emerged as good grist for the $21^{\text {st }}$ century conversations moving forward: 1 ) the divergent perspectives on definition, dimensions of practice and accountability, 2) the value of translational scholarship bridging science and complex practice, and 3) the importance of leveraging systems support for field building.
\end{abstract}

\section{Editors' Introductory Notes}

This special issue of the Journal of Youth Development: Bridging Research and Practice highlights the issues in youth development research and practice that have influenced our growing field in the $20^{\text {th }}$ century. When this journal's editorial board decided to publish a special issue commemorating the 100th anniversary of many national youth-serving organizations founded between 1907 and 1914, we three guest editors saw a tremendous opportunity to reflect on research trends and contributions that have influenced the field over time and also to consider issues of practice that continue to evolve and challenge the field. The editorial board 
generated an initial list of compelling topics to be considered and identified a number of contributing authors. As co-editors, we then invited additional authors to fill out the storyline of how youth development organizations and programs have been studied and delivered throughout the last century.

The frame for the special issue is bridging research and practice around youth development in organizational settings and with attention to the impact on the lives of young people. It is intended to speak broadly to the field and take a view larger than any single youth organization. The title, "Reflections on a Century of Youth Development Practice and Research," emphasizes a historical perspective as well as research findings and critical observations that have shaped youth development research and practice in youth-serving organizational settings - as well as exploration of the challenges that continue for researchers and practitioners.

In this introductory article, we begin with some historical context for the practice and study of youth work. This is followed by an overview of the ten thought-provoking articles and editors' observations and comments stimulated by the process of reviewing the manuscripts and working with the authors on their development. Inevitably, not all ideas and issues are covered; notably, policy implications of research and practice are largely absent. Yet collectively, these articles begin to provide a retrospective account of youth development over the years, covering such issues as how youth development has been studied, understood and measured to how youth development practice has evolved to support, engage and address the needs of young people.

\section{The $20^{\text {th }}$ Century Context for 100 Years of Youth Work}

The journey from early youth work to modern-day youth development programs is the evolution of an idea over time. The early years of the $20^{\text {th }}$ century were a time of great social, political and economic change for Americans. The historic works of Lawrence Cremin (1964, 1988) tell the story well. Cremin cites the rise of Progressive Education, the expansion of scientific methods, attention to social welfare and human rights, and the impact of urbanization, industrialization and immigration as key features shaping the lives of individuals and the missions of organizations in the early 1900s.

In 1900 most American women could not vote and they would wait another 20 years to do so. The U.S. Census Bureau lists the median age of the male population at 23 years and females at 22 years; more than half of the population of 76 million was under 23 years of age. There were no radios and no movies. There were an estimated 8,000 automobiles and 10 miles of paved roads. Social activism and reform focused on anti-child-labor laws, the expansion of public education, battles to extend the vote and eliminate corruption in politics and industry, as well as to emphasize scientific solutions to problems of the day. Progressive educators promoted childcentered learning and John Dewey's philosophy of experiential learning coincided with the rise of juvenile organizations. Religious communities, the temperance movement, settlement houses and various clubs for young men sponsored public events, study groups, athletic competitions and Sunday schools for young people in the $19^{\text {th }}$ century. But the momentum for organizational support for youth activities really took off in the first 20 years of the $20^{\text {th }}$ century.

Youth organizations founded, imported and promoted during this time reflect the priorities and concerns of the young nation. Jane Addams and an army of settlement house workers engaged poor urban and immigrant children in learning for life in America. Luther Halsey Gulick and his wife Charlotte founded Camp Fire Girls to promote physical fitness and skills befitting a wife and mother. Elizabeth Cady Stanton fought for play grounds in urban settings while the YMCA 
promoted attention to the body, mind and spirit of young men. Ernest Thompson Seton's passion for woodcraft lore influenced the Boy Scouts of America as well as the dozens of clubs and organizations which took children to the woods to explore nature and learn life skills not taught in the schools. Generally these organizations had missions grounded in health and wellbeing, family roles, citizenship, cultural and national pride, handicrafts, and skills for everyday life and work.

From the beginning, these organizations were not themselves progressive in the sense of being advocates for educational reform, youth policy or youth advocacy more broadly. They sat largely outside the world of policy creation and active reform. They were adult-led organizations with agendas driven by adult concepts of what young people needed and should be doing. They valued the spirit and energy of young people which could be mobilized for the betterment of neighborhoods, communities and families. Most of the organizations coalesced around the explicit values of the sponsoring adult leadership such as the fraternal order of Masons (Order of DeMolay, 1919 and Order of Job's Daughters, 1920), the agricultural National Grange (National Grange Junior, 1888), and Hadassah (Young Judaea Hashachara, 1909).

Group work in these settings typically focused on personal development, leadership within the faith, cultural or fraternal community value framework, and pursuit of common interests. These organizations grew organically from the interests and events of the day. They came to be recognized by affiliation (faith, sports, outdoors, gender) not by academic discipline or field of study. They were associated with space, place and environment more than with a common theory, research base or academic specialty. Today the practice of youth work is a vibrant mix of programs ranging from athletics to leadership, from small group work to national conventions, from personal growth to community revitalization.

Through the 1950s many community-based youth organizations depended on adult volunteer leaders and met in the out-of-school time in groups organized in small units like clubs or troops. Fun, friendships and active learning flourished in these settings. Between 1960 and 1980, in response to a moral panic around young people and their perceived potential for troublesome, criminal, self-destructive and generally bad behavior, new youth programs were organized and the older organizations adopted programs around drug prevention, anti-drunk driving campaigns (reminiscent of the temperance movement), pregnancy prevention, and productive alternatives for troubled, vulnerable, at-risk youth. This period is noteworthy in its embrace of the medical model of problem diagnosis and "fixing kids." By the 1980 s one begins to see the growing enthusiasm for programs that build or develop young people in positive, normative ways. Thus enters the concept of youth development, a descriptor widely recognized today but still lacking a firm definition agreed upon across the field.

\section{The $20^{\text {th }}$ Century Context for Applied Research on Adolescents}

By the early 1900s the American people generally expressed confidence that science and technology had the capacity to solve problems facing the nation. The history of linking observation and experimentation is long, but in the early years of the $20^{\text {th }}$ century the concept of linking scientific research to practice, education and training in order to impact real-world problems blossomed. For instance, the Extension land grant system of Agricultural Experiment Stations demonstrated the value of linking university-based laboratory research and field experiments to hands-on training for farmers. The scientist and the practitioner worked together to find solutions to problems, create new plant and animal varieties, and increase production and productivity. Statistics were king and experimental methods reigned supreme in agriculture as in many other disciplines. 
The integration of research and practice in areas such as education, youth work, recreation, playground work or other areas of child and youth provision was slower to develop and was less intentional than it was in medicine and other established academic disciplines. John Dewey instituted the idea of a laboratory school associated with the University of Chicago as a community-based classroom for scholars and teachers in training. Laboratory schools and child care centers were common campus institutions throughout most of the $20^{\text {th }}$ century. Springfield College in Springfield, Massachusetts became the training center for YMCA leaders and field secretaries for many years, but was not closely linked to any research institution or tradition of active field research.

For much of the century, those doing group work with or on behalf of children and young people relied on research theories and findings in education and human development focused on individual development. The adolescent was studied, not the context for working with adolescents in arenas beyond the classroom. Standardized tests were popular and highly valued as measures of normalcy or deviance. Likewise, the outcomes of prevention and intervention efforts were measured in terms of individual change with minimal attention to the nature and role of the contexts, relationships, and engagement strategies associated with that change.

The focus on the individual began to change in the 1970s. The article by Lerner and colleagues in this issue provides a valuable review of the scholars who studied adolescents from a developmental perspective and contributed to the research base the youth development field draws upon today. Theories such as attachment, resiliency and protective factors acknowledged Urie Bronfenbrenner's articulation of an ecological model of human development (1976). Explorations of the ecology of young people's development had a great influence on professionals working with children, youth and families in the last quarter of the century. Bronfenbrenner advocated studying young people in their context, paying attention to the role people and interactions played in the research. He promoted research of discovery and understanding in addition to experimental studies and hypothesis testing. His work was conceptually instrumental in bringing researcher and practitioner closer in the process of study.

In the 1970s the articulation of positive youth development concepts was gaining use in policy contexts as well as in applied research focused on social group work. One such attempt was a 1973 report commissioned by the Federal Department of Health, Education and Welfare which framed a concept of positive development grounded in fundamental human rights with application across physical, social, emotional, cognitive and moral domains (Konopka, 1973). It was intended to be a guide for a national youth policy, but the policy part never happened. However the document became a practical example of how the basic developmental needs of adolescents could be incorporated into the intentional design of youth programs almost regardless of organizational sponsorship or individual missions. A national training program for youth organization executives and staff followed with support from the Lily Endowment. While it died when the funding stopped, it too serves as a historical moment that transcended organizational boundaries and tried to unpeel the onion-like layers of complexity that still define the practice of youth work today.

Defining the field of youth development remains a challenge. In the late 1990s Stephen Hamilton made an observation that continues to ring true today (Hamilton \& Hamilton, 2004). The term "youth development" is used in at least three different ways, referring to a natural process of development, principles, and practices. All three are important, and they are logically related. Each of the articles in this special issue works from this definition-or insight-in one 
way or another. Whether "youth development" is a process, a set of principles, or a practice depends on who is looking at it.

Hamilton made another important point: The practice of youth work preceded research on the practice. "The youth development movement began with professionals and volunteers engaged day-to-day with young people in their communities, in Boys and Girls Clubs, parks and recreation programs, faith groups, families, essentially in settings or contexts other than schools ... Y Youth development is not unique in arising from practice" (Hamilton \& Hamilton, 2004, p. ix). By linking current practice to the history of youth work practice in the United States, we see the evolution of an idea more clearly and come to understand that the practice of youth development did not begin in the 1990s as much of the literature would suggest. Given the way that the terminology is both new and philosophically entwined with the traditions and history of hundreds of youth organizations, we can understand the confusion that arises when we start talking youth work practice and youth development research - just as we encounter questions when we begin to parse process, principles and practice. Readers of the articles presented here will recognize some of the ambiguity and fuzzy borders characteristic of the field.

\section{Special Issue Overview}

In "Trends in Research Topics in the Youth Development Research Field," Robert Barcelona and William Quinn (2011) present an analysis of the content of published articles on youth development research in five top-tier journals with the terms "adolescence" or "youth" in the title. Their analysis shows that only $13 \%$ of the articles in these journals take a positive youth development approach, which raises important questions about the attention Tier I research journals devote to problems and deficit behavior. They observe that research on youth is not the same as youth development research, a term that in itself is challenging to define. Their review of the last decade raises issues around the need for publishing alternatives for research on applied youth development and analysis of practice.

In their article, "Positive Youth Development: Models, Meanings and Measures," Richard Lerner, Jacqueline Lerner, Selva Lewin-Bizan, Edmond Bowers, Michelle Boyd, Megan Kiely Mueller, Kristina Schmid and Christopher Napolitano (2011) use Hamilton's process-principles-practice definition of youth development to structure an invaluable summary and discussion of the most influential scholarship undergirding each dimension of youth development. Their article reviews different theoretical models of the developmental process, major conceptual frameworks for infusing positive youth development into practice, and examples of organizations and programs guided by a positive youth development approach. The authors argue the need to systematically integrate the three dimensions of youth development scholarship and practice in order to better understand the dynamic among them and move the field forward.

Jan Scholl and Amy Paster's (2011) contribution to this volume, "Locating, Analyzing and Making Available a Century of 4-H Research Studies," describes a unique database they compiled that includes over 3,400 studies of the 4-H Youth Development Program conducted between 1911 and 2010. Their effort was part of the inspiration for this special issue's examination of the past 100 years. This research began with a goal of establishing the long existence of a 4-H research base. Comments on topics through the decades give a glimpse of organizational priorities over time. Although the studies in the database have not been fully analyzed, they are available for today's scholars to explore in their own work. 
In their piece, "From Then to Now: Emerging Directions for Youth Program Evaluation," Mary Arnold and Melissa Cater (2011) look back on the emergence of youth development program evaluation before considering three contemporary trends. They highlight a new focus on evaluating program quality, the current organizational consideration of capacity building, and the emerging evaluation approach of youth participatory evaluation. These trends raise questions about the traditional "gold standard" of impact studies in light of scarce resources for evaluation and different accountability demands.

Stephen Russell and Kali Van Campen (2011) contribute to the conversation in "Diversity and Inclusion in Youth Development: What We Can Learn from Marginalized Young People," which provides a critique of the ways that the large national youth organizations founded at the beginning of the $20^{\text {th }}$ century have engaged-or not-with new immigrant and GLBT youth, two groups that are marginalized by organizations. The reader is challenged to recognize the basic family constructs and cultural traditions that must be recognized and addressed if marginalized young people are to be welcome and included.

In "The Many Faces, Features and Outcomes of Youth Engagement," Rebecca Saito and Theresa Sullivan (2011) report on research conducted to identify the core elements that are common to youth program models featuring youth engagement at various levels and in different ways. Created by practitioners in response to a comprehensive literature review and the filter of their own experience, their Rings of Engagement offer a model that can be applied to youth-adult partnerships, service learning, youth leadership and other youth engagement program designs and strategies.

The important role youth workers have historically played in youth work practice is explored in "The Evolving Role of Youth Workers," by Lynne Borden, Gabriel Schlomer and Christine Bracamonte Wiggs (2011). Their discussion of what might be gained and lost in the push to certify or professionalize the youth development field raises the questions of whether youth development is a field of practice, a profession, a discipline, an approach or even an epistemological construct that applies to many allied practices and related fields such as social work, formal education, recreation, residential care, afterschool and youth organizations.

In "Voluntary Youth-Serving Organizations: Responding to the Needs of Young People and Society in the Last Century" Suzanne Le Menestrel and Lisa Lauxman (2011) examine the early mission statements of 14 early national organizations providing programs and opportunities for young people, and then compare early iterations to present mission language. Their approach introduces major points in the evolution from older youth group work practices to things shaping youth development work today. Their organizational matrix emphasizes the variety, long life and responsiveness of these organizations.

Reed Larson and colleagues were asked to consider new directions for research. In "New Horizons: Understanding the Processes and Practices of Youth Development," Larson, Kang, Perry and Walker (2011) startle us to attention when they claim, "We know a lot about youth development, and we know very little." In a plea to recognize the complexities of practice in order to strengthen research, the authors use practical examples and suggestions to illustrate the issues they raise for the field.

Finally, Dale Blyth was invited to discuss issues that have the potential to impact the direction of the youth development field in the $21^{\text {st }}$ century. In "The Future of Youth Development: Multiple Wisdoms, Alternate Pathways and Aligned Accountability" he highlights some of the 
landmark events, publications and people who have shaped the out-of-school time world of youth development programs in the $20^{\text {th }}$ century (Blyth, 2011). He makes the case that it will take a more varied approach to research on processes, principles and programs as well as more serious collection of quantitative data in order to build a strong youth development field. Lastly, he offers a metaphor for conceptualizing program impact and a view of aligning accountability for funders and policy makers.

Together these articles represent an evolving understanding of youth development program practice and research. They shed light on how far the field has evolved, just as they stimulate critical reflection on the issues and challenges that we carry forward.

\section{Editors' Reflections}

Youth development is a very broad, interdisciplinary field. No single journal issue could deal comprehensively with a century of research and practice. But the articles in this issue do represent a variety of influential perspectives guiding scholarship, evaluation, practice, organizations, and policy in the field today.

The thoughtful articles in this volume give much reason to be optimistic about youth development as a vibrant practice and as a focus for substantive research. Reading the submissions and working with the authors to craft a cohesive volume was an exciting assignment. It presented an opportunity to look at ideas through new eyes and to reflect on many of the trends and issues of our field as raised by these authors. As we reflected across the articles, three important themes emerged for us that seem to be good grist for the $21^{\text {st }}$ century conversations moving forward:

- the divergent perspectives on definition, dimensions of practice and accountability,

- the value of translational scholarship bridging science and complex practice, and

- the importance of leveraging systems support for field building.

\section{Divergent Perspectives on Definition, Dimensions of Practice and Accountability}

There are a number of issues in the field about which wise and well-intended people simply do not agree. They include tensions around definition, dimensions of practice and accountability. These issues have implications for the practice, applied research and policy dimensions of this work moving forward, and these tensions present both opportunities and challenges in different ways for different subsets of players. They are grounded in historic traditions, academic disciplines, institutional alliances and organizational imperatives. The key question is whether to push quickly for resolutions or move more slowly to establish greater common ground for the field.

First, there is no consistent usage or agreed upon definition of youth development. This presents problems in general when speaking to those outside the youth development field and particularly when representing U.S. practice and research to international colleagues. Hamilton named this issue in the late 1990s, yet we still lack consensus. In this volume, Barcelona and Quinn (2011) anchor their understanding of youth development in the world of practice. They describe youth development as an approach to working with young people that is grounded in the social and group nature of programs. They raise the question about the vague nature of the term "youth development research," and question how this is the same or different from research on adolescents. In their article, Lerner and colleagues (2011) have adopted the term "positive youth development" or PYD which seems to focus on young people while striving to 
incorporate the principles and context shaping practice. Depending on the audience and purpose, the field may be referred to as youth development, after-school, out-of-school time, informal education, complementary learning, expanded learning opportunities or nonformal learning (to name but a few). These are not irrelevant distinctions; they mean slightly different yet significant things to different people. The question becomes, does the field draw strength from this breadth of understanding or is it weakened by the absence of a single understanding of the kinds of setting and programs that comprise the youth development field?

A second related issue is lack of agreement on important dimensions of youth development practice, in terms of both which practitioners are included as well as how to advance the profession. Borden et al. (2011) provide one broad, all-encompassing definition while others prefer distinct descriptions that have meaning to a particular sector and represent the nuanced nature of specific types of work. Related is the debate about professionalization and credentials for adults working with and on behalf of young people. While youth workers generally seek the respect and higher levels of compensation associated with professionalization, some raise concerns about reducing practice to concrete, universal, procedural knowledge for fear of stripping youth work of its essence or about professionalization serving a gatekeeping function. Is the greater wisdom in establishing a single collective identity and profession or does the strength of the field reside in the variety and independence of the different sectors?

A third area of tension involves accountability associated with research and program evaluation. There is a continual call from funders and policy makers for evidence that youth programs make a positive difference in the lives of young people, and for clarity about how impacts are achieved. Practitioners and researchers alike regularly adjust their programmatic and research agendas to fit ever-changing funding demands and priorities. We move across focusing on academic success, personal and social skills, program quality or positive impacts on society. While it is widely recognized that the field gains strength from a solid, scientific, experimental research base, many argue that youth development in program settings can best be understood naturalistically, ecologically, synergistically and culturally (see Larson et al., 2011). As Arnold and Cater (2011) note, a limiting factor is that strong research and evaluations take time, money and knowledge resources, things that most youth serving organizations do not have.

These competing positions and needs can be read as signs of discord, or as signs of the vital unfolding of the field. They are anchored in the ambiguity and the complexity of youth development research and practice. It is possible that these varied understandings and perspectives are a natural consequence of a practice-based history, interdisciplinary grounding and dedication to work with young people, a demographic about whom society still has very mixed impressions and opinions. The character of youth work and whether it is primarily about intervention, prevention or promotion is fundamentally related to whether young people are individuals with human rights or a category of people who must continually prove their value and try to influence what adults believe about them.

Responding to impatience from funders, policy makers and the field itself, there is a tendency to "just do something" to address legitimate concerns about the boundaries, qualifications and accountability of youth programs, often without acknowledging the complexities involved in all these dimensions. In such a climate, it is tempting to impose the kinds of rules, structures and procedures that have been accepted by some other fields albeit not always in the best interest of young people. But in the big picture (think medicine, law, education) we are a young field. In this $21^{\text {st }}$ century, we should take the time to define the field more clearly and to decide where to be open and flexible, and where to be more prescriptive. This should be guided by the 
lessons of history, the converging findings of research, the missions and purposes of organizations, the philosophy and beliefs of youth workers, the requirements and accountabilities of funders, the needs of young people, and the priorities of families and communities.

\section{The Value of Translational Scholarship Bridging Science and Complex Practice}

The arena of translational scholarship is one with great promise to strengthen and focus the youth development field on the issues of importance. There are professions where the bridge between science and complex practice is soundly constructed. The field of professional medicine deals with the full complexity of the human system-the body-and it has an effective mechanism for bridging scientific knowledge directly into practice. That mechanism is the doctor. This highly trained, highly skilled, highly paid practitioner is taught the disciplinary foundations (e.g., biology, chemistry, physiology, pharmacology) that contribute to understanding how to promote health and treat disease. The education and apprenticeship process is a lengthy one. Doctors are taught how to assess new findings from research in these contributing disciplines and translate them into evidence-based practice. Because the human system is so complex, the field of medicine split into distinct specialties around each of the body's systems. We have no comparable bridging in our field to deal with the full complexity of the system of psycho-social development and to promote social/psychological health and development.

We are not advocating that youth work follow in the footsteps of medicine. We do, however, need to fill these functions of distilling, translating and disseminating good science on human development into the daily practice of promoting youth development. There is increasing recognition that young people are complex, developing organisms that need to be understood holistically in order to promote the achievement of positive life outcomes. In the last 10 years scholars such as Richard Lerner, Peter Scales, James Connell and Michelle Gambone, as well as the National Research Council, have begun to translate the science of developmental research into the practice of youth development. But there have been no significant commitments of funds or avenues to systematically take the frameworks and implement and study them as a piece.

In order to move forward in any meaningful way with achieving population-wide healthy outcomes for youth, we need systematic approaches to work on these bridging functions:

- distill research findings and translate them for practical application,

- create and make available tools for teaching and training,

- study and test the new strategies in practice settings, and

- make findings and recommendations for practice widely available.

At present, important new research relevant to work with young people is largely inaccessible to the working professionals who need it the most. There is a pressing need for a coordinated, ongoing effort to sort and disseminate findings from developmental science so that what is learned can be put into practice. A systematic effort or process is required to distill the most important findings from academic/scientific research from multiple disciplines (e.g. psychology, sociology, education) on an ongoing basis, translate them into what people working with youth should $d o$ and disseminate this knowledge.

For example, just in this volume (Lerner et al. 2011; Russell \& Van Camp, 2011) there is a wealth of important research referenced that can and should play a key role in what 
developmental supports are put in place for young people. This includes research on sense of purpose, assets, motivation, active engagement, systems theory of context influences, resilience, thriving, diversity and inclusion. Barcelona and Quinn (2011) point out that professional journals often ignore practice and fail to provide sorting mechanisms to identify the processes and experiences that are the most important in the day-to-day practice with youth.

The creation of training and curricula follows the identification of important social psychological mechanisms, setting features and such. Currently each organization is left on its own to either develop or purchase curricula that fit their mission, if any are available. For example, we know the critical importance of including youth in meaningful decision making across all settings, but any youth worker will tell you that they need tools and training on how to do this effectively. Even with a large scale effort like the National Research Council research summary (2002) there was no follow up with creating training and tools based on the findings.

Once the tools for application are created and made available, practitioners and researchers together need the opportunity to practice, refine and study their effectiveness in learning laboratory like settings. Reciprocal respect and collegial inquiry are required to make this successful. In medical science there is a clear recognition of the need to study processes first in a controlled setting using rigorous methodology where important factors can be controlled and varied. In the science of human development we try to implement the same rigorous scientific methodology in uncontrolled environments with too many variables. We are bombarded with calls for "gold standard" experimental design research, but we are left with having to try to figure out how to graft this type of research onto naturally occurring programs that have their own history, systems, needs and agendas. We have not had a systematic process of ongoing refinement and restudy that allowed us to actually determine what could work. We need something more like the High Scope learning lab that yielded a wealth of practice standards, training and curricula that changed the face-and effectiveness-of early child care.

At the same time we cannot ignore the importance of having scientists move into the naturally occurring settings of youth programs and organizations. Understanding the complexity of the relationships among setting features, activities and the development of the human being requires deep research to begin to untangle associations and develop hypotheses for study in more controlled environments. Translational scholarship with researchers and practitioners mutually engaged around the common thread of youth development has the potential to align the field around a defined interdisciplinary core to the benefit of both.

\section{The Importance of Leveraging Systems Support for Field Building}

In framing this special issue, the editorial board expressed a preference to focus on research related to programs and organizations; consequently attention to youth policy and supportive systems (such as intermediaries, foundations, collaborations and networks) is largely absent. Still, our editorial conversations kept circling back to the idea that a broad research approach over time along with serious attention to translational scholarship has great potential to influence the contested issues, and to gradually bring greater consensus, definition and alignment to the youth development field.

Blyth (2011) makes a compelling argument that real impact happens and important discoveries are made within the program environment. Likewise Larson and colleagues (2011) argue that more program level observation will benefit scholars and practitioners. Neither suggests an emphasis on programs alone. Yet the inclination of people inside and outside the field to see youth development practice simply as a collection of programs can mask the critical nature of 
systems support that is required if the field is to grow and thrive. Strong and influential systems play a critical role in influencing youth policy, creatively linking systems impact and public accountability, and supporting the bridging work that serves the field broadly. Examples include the Carnegie Council of Adolescent Development's report A Matter of Time: Risk and Opportunity in the Nonschool Hours (1992), the Forum for Youth Investment's policy and professional development contributions, and the W.T. Grant Foundation's continued commitment to research and scholarly excellence in the field.

Perhaps it is in attention to systems building, translational scholarship, and research and practice clearly labeled as youth development that the field of youth development will come to maturity. With strong system support for professional development, quality improvement, scholarly opportunities for practitioners in referred journals, and effective bridging of scientific research and practice, many of the conundrums of definitions, boundaries, professionalism and accountability will work themselves out in logical sequence. With systems to support full rights and participation of young people, organizations and programs will more easily accept the robust role young people can play in their personal growth and development.

As editors, we thank the editorial board of the Journal of Youth Development Bridging Research and Practice for the opportunity to work with contributing colleagues to frame these ideas and critiques of issues in the field of youth development in the $20^{\text {th }}$ century. The process certainly inspired us - and we hope these articles stimulate conversations and thinking for you as well.

\section{References}

Arnold, M.E., \& Cater, M. (2011). From Then to Now: Emerging Directions for Youth Program Evaluation. Journal of Youth Development, 6(3). Retrieved from http://web.memberclicks.com/mc/page.do?sitePageId=101250\&orgId.naeha

Barcelona, R.J., \& Quinn, W. (2011). Trends in Youth Development Research Topics: An Integrative Review of Positive Youth Development Research Published in Selected Journals Between 2001-2010. Journal of Youth Development, 6(3). Retrieved from http://web.memberclicks.com/mc/page.do?sitePageId=101250\&orgId.naeha

Blyth, D.A. (2011). The Future of Youth Development: Multiple Wisdoms, Alternate Pathways, and Aligned Accountability. Journal of Youth Development, 6(3). Retrieved from http://web.memberclicks.com/mc/page.do?sitePageId=101250\&orgId.naeha

Borden, L.M., Schlomer, G.L., \& Wiggs, C.B. (2011). The Evolving Role of Youth Workers. Journal of Youth Development, 6(3). Retrieved from http://web.memberclicks.com/mc/page.do?sitePageId=101250\&orgId.naeha

Bronfenbrenner, U. (1976). The experiential ecology of education. Educational Researcher, 5(9), 5-15.

Cremin, L.A. (1964). The transformation of the school: Progressivism in American education, 1876-1957. New York: Vintage Books. 
Cremin, L.A. (1988). American education: The metropolitan experience 1876-1980. New York: Harper \& Row.Hamilton, S.F. \& Hamilton, M.A. (Eds). (2004). The youth development handbook: Coming ofage in American communities. Thousand Oaks: Sage.

Konopka, G. (1973). Requirements for healthy development of adolescent youth. Adolescence, $8(31), 2-25$.

Larson, R.W., Kang, H., Cole Perry, S., \& Walker, K.C. (2011). New Horizons: Understanding the Processes and Practices of Youth Development. Journal of Youth Development, 6(3). Retrieved from http://web.memberclicks.com/mc/page.do?sitePageId=101250\&orgId.naeha

LeMenestrel, S.M., \& Lauxman, L.A. (2011). Voluntary Youth-Serving Organizations: Responding to the Needs of Young People and Society in the Last Century, 6(3). Retrieved from http://web.memberclicks.com/mc/page.do?sitePageId=101250\&orgId.naeha

Lerner, R.J., Lerner, J.V., Lewin-Bizan, S., Bowers, E.P., Boyd, M. J., Kiely Mueller, M., et al. (2011). Positive Youth Development: Processes, Programs, and Problematics. Journal of Youth Development, 6(3). Retrieved from http://web.memberclicks.com/mc/page.do?sitePageId=101250\&orgId.naeha

National Research Council and Institute of Medicine. (2002). In J. Eccles \& J. Gootman (Eds.), Community programs to promote youth development. Washington, DC: National Academy Press.

Russell, S.T., \& Van Campen, K. (2011). Diversity and Inclusion in Youth Development: What We Can Learn from Marginalized Young People. Journal of Youth Development, 6(3). Retrieved from http://web.memberclicks.com/mc/page.do?sitePageId=101250\&orgId.naeha

Saito, R.N., \& Sullivan, T.K. (2011). The Many Faces, Features and Outcomes of Youth Engagement. Journal of Youth Development, 6(3). Retrieved from http://web.memberclicks.com/mc/page.do?sitePageId=101250\&orgId.naeha

Scholl, J., \& Paster, A. (2011). Locating, Analyzing and Making Available a Century of 4-H Research Studies, 1911-2010. Journal of Youth Development, 6(3). Retrieved from http://web.memberclicks.com/mc/page.do?sitePageId=101250\&orgId.naeha

(C) Copyright of Journal of Youth Development Bridging Research and Practice. Content may not be copied or emailed to multiple sites or posted to a listserv without copyright holder's express written permission. However, users may print, download or email articles for individual use. 